\title{
Obesity in Pets - One Health and Animal Welfare Considerations
}

\author{
Shane Ryan \\ World Small Animal Veterinary Association \\ c/o Companion Animal Surgery Pte. Ltd \\ Singapore \\ shane.ryan@wsava.org
}

\begin{abstract}
Companion animals - particularly and most commonly dogs and cats - share the lifestyles and the environments of their human counterparts. Similarly, they may also share both the positive and negative implications of this "intimate relationship" with humans. Improved access to resources such as food supplies, shelter, security \& veterinary care may be considered positive aspects of this relationship. Negative implications can include, for example, a sedentary lifestyle with limited exercise opportunities that may cause increased rates of metabolic or degenerative diseases such as Type 2 diabetes, cardiovascular disease, osteoarthritis as well as certain neoplasias.
\end{abstract}

One of the most significant human healthcare issues, and one often shared by companion animals is the growing problem of obesity. The presentation offers an overview of interaction of environmental \& social factors that can have adverse influence on the health and welfare - especially in relation to the "the rising pandemic of obesity" - of humans and companion animals.

Keywords - cat; dog; human; obesity; One Health; animal welfare

\section{One Health}

One Health is the intersection of veterinary medicine, human health and environmental science. It is interdisciplinary, promoting collaboration - and potentially further, integration - of all aspects of the health care for humans and animals. This necessarily includes the medical, veterinary and allied health professions, epidemiologists and public health experts, ecosystem and climate scientists, researchers and others.

One Health is not a new concept. Rudolf Virchow, the German physician known as the "father of comparative medicine and modern pathology"1 declared in the mid- $19^{\text {th }}$ century that

"Between animal and human medicine there are no dividing lines-nor should there be"

This was built on still earlier approaches. For example, Claude Bourgelat, who, when establishing the world's first veterinary school in Lyon in the 18th century, recommended a comparative approach to human and animal medical science. ${ }^{2}$ Following on from Virchow, the Canadian physician Sir William Osler espoused modern One Health collaborative principles during the late $19^{\text {th }}$ and early $20^{\text {th }}$ centuries. $^{3}$

However, during the early years of the $20^{\text {th }}$ century, interest in the concept of One Health has been declined. This has, in part, been attributed to the end of the reliance on animals for transport (replaced by the internal combustion engine) ${ }^{4}$ and possibly to increased urbanisation and the rapid improvements in human medical science.

The modern re-emergence of "One Health" in the mid-1960s followed the recognition of the close association between animal and human health and medicine by the American veterinarian Calvin W. Schwabe, who then formalised the concept as "One Medicine" in the $19843^{\text {rd }}$ edition of the textbook "Veterinary Medicine and Human Health." 1, 4,5,6

Following the response to potential global pandemics, including the Highly Pathogenic Avian Influenza (HPAI H5N1) outbreak during the first decade of the 21 st century, and recognising the risks of other emerging zoonotic diseases, "One Medicine" evolved via a tripartite agreement between the FAO, WHO and OIE into the present "One Health" framework. ${ }^{3}$ Subsequently, the first international One Health scientific congress was held in Melbourne, Australia in February 2011 . $^{7}$ 
However, "One Health" involves more than infectious or zoonotic diseases. In developed nations, much of the focus of veterinary medical practice has shifted from the wildlife-interface boundary and from production animals in rural communities to companion animals in urban centres. There is increasing emphasis on the "human-animal bond" which may be defined as:

"a mutually beneficial and dynamic relationship between people and animals that is influenced by behaviors that are essential to the health and wellbeing of both. This includes, but is not limited to, emotional, psychological, and physical interactions of people, animals, and the environment." 8

\section{Companion Animals in One Health}

Companion animals - particularly and most commonly dogs and cats - share the lifestyles and the environments of their human counterparts. Similarly, they may also share both the positive and negative implications of this "intimate relationship" with humans. ${ }^{9}$ Improved access to resources such as veterinary care, shelter, security $\&$ food supplies may be considered positive aspects of this relationship. Negative implications can include, for example, a sedentary lifestyle with limited exercise opportunities that may cause increased rates of metabolic or degenerative diseases such as Type 2 diabetes, cardiovascular disease, osteoarthritis as well as certain neoplasias.

\section{Obesity}

One of the most significant human healthcare issues, and one often shared by companion animals is the growing problem of obesity. ${ }^{10}$ In many countries, human obesity can be regarded as a "rising pandemic." 11

A recent paper from the Global Burden of Disease (GBD) 2015 Obesity Collaborators looked at international trends over a 25-year period (1990 2015) in the incidence of over-weightedness and obesity among human adults and children. Metaanalysis of data from 68.5 million people in 195 countries revealed a rapid increase in the prevalence of and disease burden associated with an elevated body-mass index (BMI). Over the 25 years, the prevalence of obesity had doubled in more than 70 countries and had continuously increased in most others. ${ }^{11}$ While the 2015 global obesity prevalence was $5.0 \%$ among children and $12.0 \%$ among adults there was considerable variation between nations. For example, the adult obesity rate in Egypt was $35.3 \%$, in Vietnam it was $1.6 \%$; while childhood obesity was highest in the United States (12.7\%) and least in Bangladesh (1.2\%). ${ }^{11}$
Veterinary research on the extent of weight problems in dogs and cats has not kept pace with that of human medical science. ${ }^{12}$ However, studies have been undertaken, primarily in Australia, New Zealand, North America and Europe to gauge the prevalence of over-weightedness or obesity in canine and feline populations. A large American general veterinary practice group (Banfield Pet Hospital) sees 2 million dogs and $1 / 2$ million cats annually (2012). When reviewing their medical data covering the 5 years between 2007 - 2011, the incidence of overweight and obesity increased by $37 \%$ in dogs and $90 \%$ in cats reflecting the increasing trend in prevalence of human obesity. ${ }^{13}$

The reported prevalence of overweight and obese companion animals ranges widely, from 19.7 $59.3 \%$ in dogs \& $11.5-52 \%$ in cats. ${ }^{9}$ There is no universally accepted scale for defining overweightedness or obesity in pet animals ${ }^{12}$ although the Body Condition Score (BCS) is commonly used. ${ }^{14}$ While there is reportedly good correlation between BCS and more advanced measures of body fat e.g. dual energy X-ray absorbtiometry (DEXA) scanning, ${ }^{12}$ a recent Danish paper suggested this method (BCS) tends to under-report the level of obesity (in cats). ${ }^{15}$

\section{Co-morbidities}

In humans and in companion animals, obesity may predispose to a variety of metabolic, endocrinological, degenerative, reproductive \& neoplastic diseases.

In people, obesity is a significant risk factor for the development of metabolic syndrome, insulin resistance and (Type 2) diabetes mellitus (DM), hypertension and stroke, coronary artery disease, osteoarthritis and gout, respiratory diseases including asthma and sleep apnoea, infertility and certain neoplasias especially hormone-dependent and gastrointestinal e.g. colo-rectal, prostate, ovarian, and breast. 16, 17 There may also be psychological as well psycho-social issues associated with poor body image and the stigmatisation of obese persons in certain cultures. ${ }^{17}$

A similar set of risks accompany obesity in companion animals although the risk and incidence varies between dogs and cats. Obesity is a major risk factor for cats to develop insulin resistance and hyperinsulinemia, and subsequently Feline diabetes mellitus (FDM). In 80- 90\% of spontaneous FDM, the development is similar to Type 2 in humans. ${ }^{18}$ Canine diabetes is typically Type I or insulindependent, and while obesity may not be a cause, it 
can complicate diabetic treatment due to decreased insulin sensitivity. ${ }^{9,16}$

In pets, especially dogs, being overweight significantly predisposes to orthopaedic disease, particularly osteoarthritis as well as possibly humeral condylar fractures and cranial cruciate ligament rupture (in cocker spaniels), and it has been hypothesized that obesity and lack of postural muscle strength may increase risk of intervertebral disc disease. ${ }^{19}$

Obesity is an important risk factor for the development of tracheal collapse in small dogs, and can exacerbate brachycephalic obstructive airway syndrome. ${ }^{20}$ Obese dogs are at significantly higher risk of heat-stroke. Obesity may affect heart function with detrimental effects on cardiac rhythm, increased left ventricular volume, blood pressure, and plasma volume.

The risk of development and/or progression of neoplasia has not yet been studied adequately in companion animals to confirm a strong relationship with or causation due to obesity - most studies have been retrospective in design and small in scale. ${ }^{9}$ However, a small number of studies have reported association between obesity and mammary carcinoma and increased risk of developing transitional cell carcinoma of the bladder in dogs. ${ }^{16}$, 21

With dogs and cats, being overweight is obviously not likely to result in psychological issues such as low self-esteem. However, a questionnaire based study looking at the health-related quality of life (HRQOL) in dogs, found that after a successful weight-loss program, along with increased physical activity, animals showed decreased signs of emotional disturbance and pain. ${ }^{22}$

\section{Animal Welfare}

There is no single definition of animal welfare that has met with universal acceptance. What is regarded as optimal or sub-optimal welfare may vary depending on cultural, scientific, religious and social-economic circumstances. $^{23}$ However, a simple proposed concept is that animal welfare requires not only health and a lack of stress, but "is dependent on what animals feel." 24 This "feeling" refers to both physical and mental states, and thus reflects not just on physical health and fitness, but also the emotional or psychological, and thus quality of life (QOL).

Overweight and obese pets are compromised in both life-expectancy and HRQOL. ${ }^{12}$ Research has indicated that in laboratory animals, pigs and $\operatorname{dog} s^{25}$ a restrictive diet increases lifespan and delays onset of species-specific degenerative diseases especially osteoarthritis in dogs. However, negative welfare states such as increased hunger, stress elevation, behavioural changes (increased aggression \& stereotypies) may occur with food restriction. Thus, the inferred core "Five Freedoms," used as basis from many animal welfare systems, conflict. It is likely that the freedom from hunger, the freedom from disease, and then freedom to exhibit natural behaviour may be mutually exclusive in companion animals.

\section{Costs and Consequences of Obesity}

The rising global trend in human obesity may result serious climatic and environmental repercussions. More resources and energy are required to maintain, transport and feed the extra human "biomass," increasing energy demands and the human ecological foot-print. It has been estimated that in 2005 the overweight human population added the equivalent of an extra 242 million people globally, while obesity added another 56 million human equivalents, nearly one-third billion. ${ }^{26} \mathrm{UN}$ world 2015 population projections for 2050 indicate a possible 2.4 billion more people requiring food and shelter (total 9.7 billion). ${ }^{27}$ Increased human biomass in the form of overweight or obese individuals could have same implications for world energy requirements as an extra one-half billion persons:

Tackling population fatness may be critical to world food security and ecological sustainability. ${ }^{26}$

Being overweight or obese significantly increases risk and prevalence for variety diseases. Resultantly, the secondary costs to the individual for medical expenses, as well as increased demand on the provision of community health-care profession, rise. Citing an "an undeniable link between rising rates of obesity and rising medical spending" one study estimated the medical costs of obesity in the US to amount to US $\$ 147$ billion would by $2008 .^{28}$

However, little information is currently available on the added health-care costs of overweight or obese companion animals.

\footnotetext{
One Health Approach to Human and Companion Animal Obesity

Developing collaborations between practitioners and researchers working in human and veterinary healthcare, looking at environmental, genetic and behavioural is a goal of the One Health initiative. ${ }^{9}$ Opportunities exist for prospective interdisciplinary research into obesity in humans and companion animals given the common comorbidities and risk factors such as lifestyle and environment. ${ }^{10}$
} 
Most human weight loss programs encourage lifestyle interventions including dietary changes such as calorific restriction, increased physical activity, taking personal responsibility for one's health, social network and possibly pharmaceutical support. ${ }^{29,}{ }^{30}$ However, a major challenge following successful weight-loss is long-term maintenance. ${ }^{31}$ In addition to the many health benefits, physical activity is important in preventing weight gain and maintaining weight loss. ${ }^{10}$

A positive correlation between dog ownership and increased human exercise levels, primarily though pet walking, has been demonstrated. Subsequent health benefits may be effective in the prevention or amelioration of a number of human lifestyle-related diseases in both adults and children. ${ }^{12}$

\footnotetext{
${ }^{1}$ Monath TP, Kahn LH, Kaplan B. Introduction: one health perspective. ILAR J. 2010;51(3):193-8. PMID: 21131719. Accessed June 16, 2017.

${ }^{2}$ Day MJ. One health: the importance of companion animal vector-borne diseases. Parasit Vectors. 2011 Apr 13;4:48. doi: 10.1186/1756-3305-4-48. Review. ${ }^{3}$ Kaplan B, Scott C. One Health History Question: Who Coined the Term 'One Medicine'? 2011. Accessed June 16, 2017. One Health Initiative. http://www.onehealthinitiative.com/publications/W ho coined the term One Medicine by B Kaplan and C Scott May19 2011-CS.pdf

4 Cardiff RD, Ward JM, Barthold SW. 'One medicine - one pathology': are veterinary and human pathology prepared? Lab Invest. 2008 Jan;88(1):18-26. Epub 2007 Nov 26

5 Takashima GK, Day MJ, Setting the One Health Agenda and the Human-Companion Animal Bond. Int. J. Environ. Res. Public Health 2014, 11, 1111011120

${ }^{6}$ Schwabe CW. Veterinary Medicine and Human Health, 3rd ed. Williams and Wilkins: Baltimore, 1984, xix, pp 1-680

${ }^{7}$ One Health Global Network. What is One Health? http://www.onehealthglobal.net/what-is-onehealth/. Accessed June 16, 2017

8 AVMA. Human-Animal Bond. Accessed 17 June 2017.https://www.avma.org/KB/Resources/Referen ce/human-animal-bond/Pages/Human-Animal-

Bond-AVMA.aspx

${ }^{9}$ Chandler M, Cunningham S, Lund EM, Khanna C, Naramore R, Patel A, Day MJ. Obesity and Associated Comorbidities in People and Companion Animals: A One Health Perspective. Journal of Comparative Pathology, Volume 156, Issue 4, May 2017, Pages 296-309

10 Day MJ. One Health Approach to Preventing Obesity in People and Their Pets. Journal of Comparative Pathology Volume 156, Issue 4, May 2017, Pages 293-295
}

The People and Pets Exercising Together (PPET) Study evaluated leveraging the human-companion animal bond and the role pets play in providing social support in a combined people and pets (PP) weight loss program. ${ }^{21}$ The study's one-year trial results indicated the effectiveness of joint calorific restriction and physical activity (and monitoring) programs for mutual weight loss in both humans and dogs, and recommended that consideration of social support for weight loss in people i.e. family members, friends and co-workers, be extended to include pets. $^{21}$

It is also suggested that physical activity should be recorded as a "vital sign" in the health histories of people and companion animals. ${ }^{10}$

\author{
${ }^{11}$ GBD 2015 Obesity Collaborators. Health Effects \\ of Overweight and Obesity in 195 Countries over \\ 25 Years. \\ N Engl J Med. 2017 Jun 12. doi: \\ 10.1056/NEJMoa1614362. [Epub ahead of print - \\ accessed 17 June 2017] \\ ${ }^{12}$ Sandøe P, Palmer C, Corr S, Astrup A, Bjørnvad \\ CR. Canine and feline obesity: a One Health \\ perspective. \\ Vet Rec. 2014 Dec 20-27;175(24):610-6. \\ 13 Banfield (2012) State of Pet Health Report.
} Accessed 17 June 2017

https://www.banfield.com/Banfield/media/PDF/Do wnloads/soph/Banfield-State-of-Pet-HealthReport_2012.pdf

${ }^{14}$ AAHA. Body Condition Scoring (BCS) Systems. Accessed 17 June 2017

https://www.aaha.org/public_documents/profession al/guidelines/weightmgmt_bodyconditionscoring.p df

${ }^{15}$ Bjørnvad CR, Nielsen DH, Armstrong J, McEvoy F, Hølmkjær KM, Jensen KS, Pedersen GF, Kristensen AT. (2011) Evaluation of a nine-point body condition scoring system in physically inactive pet cats. American Journal of Veterinary Research 72, 433-437

${ }^{16}$ German AJ. The growing problem of obesity in dogs and cats. J Nutr. 2006 Jul;136(7 Suppl):1940S1946S.

17 WHO. Obesity: preventing and managing the global epidemic. Report of a WHO consultation.World Health Organ Tech Rep Ser. 2000;894:i-xii, 1-253.

18 Billinghurst I. The nutritional management of feline diabetes — an evolutionary perspective. Proceedings of AVA Annual Conference, Adelaide, 2016:79-89

19 Rusbridge C. Canine chondrodystrophic intervertebral disc disease (Hansen type I disc 
disease). BMC Musculoskelet Disord. 2015; 16(Suppl 1): S11

${ }^{20}$ Packer R, Hendricks A, Tiver MS, Burn CC. Impact of Facial Conformation on Canine Health: Brachycephalic Obstructive Airway Syndrome PLoS One. 2015; 10(10): e0137496. Published online 2015 Oct 28. Accessed 18 June 2017

${ }^{21}$ Kushner RF, Blatner DJ, Jewell DE, Rudloff K. The PPET Study: People and Pets Exercising Together. Obesity Vol. 14 No. 10 October 2006

${ }^{22}$ German AJ1, Holden SL, Wiseman-Orr ML, Reid J, Nolan AM, Biourge V, Morris PJ, Scott EM. Quality of life is reduced in obese dogs but improves after successful weight loss. Vet J. 2012 Jun;192(3):428-34.

23 Biological Resource Management Connecting Science and Policy. Chapter: Animal Welfare and Product Quality January 2000 In book: Biological Resource Management Connecting Science and Policy, pp.163-171

${ }^{24}$ Duncan, IJH. Welfare is to do with what animals feel. J. Agr. Env. Ethics, 1993:6 Suppl 2, 8-14

${ }^{25}$ Lawler DF, Larson BT, Ballam JM. Smith GK, Biery DN, Evans RH, Greely EH, Segre M, Stowe $\mathrm{HD}$, Kealy RD. Diet restriction and aging in the dog: major observation over two decades. British Journal of Nutrition 2008: 99, 793-805

${ }^{26}$ Walpole C, Prieto-Merino D, Edwards P, Cleland J, Stevens G, Roberts I. The weight of nations: an estimation of adult human biomass. BMC Public Health 2012, 12:439 http://www.biomedcentral.com/1471-2458/12/439

${ }^{27}$ UN Department of Economic and Social Affairs. World population projected to reach 9.7 billion by 2050.

http://www.un.org/en/development/desa/news/popu lation/2015-report.html Accessed 18 June 2018

${ }^{28}$ Finkelstein EA, Trogdon JC, Cohen JW, Dietz W. Annual medical spending attributable to obesity: payer

and service-specific estimates. Health Affairs, 2009:28, w822ew831.

${ }^{29}$ Jensen MD, Ryan DH, Donato KA, Apovian CM, Ard JD, Comuzzie AG, Hu FB, Hubbard VS, Jakicic JM, Kushner RF, Loria CM, Millen BE, Nonas CA, Pi-Sunyer FX, Stevens J, Stevens VJ, Wadden TA, Wolfe BM, Yanovski SZ. Guidelines (2013) for managing overweight and obesity in adults. Obesity 2014;22(S2):S1-S410.

${ }^{30}$ Shearer P. Literature Review - Canine, Feline and Human Overweight and Obesity. Banfield Applied Research \& Knowledge Team. August 2010:1-8.

${ }^{31}$ Bartges J, Kushner RF, Michel KE, Sallis R, Day MJ. One Health Solutions to Obesity in People and Their Pets. J. Comp. Path. 2017, Vol. 156, 326-333. 